\title{
Patents, Nutritional Supplements, and Nutraceuticals: issues should be Revisited
}

\author{
Keywords: Patent; Nutritional supplements; Nutraceuticals: \\ Pharmaceuticals.
}

\section{Editorial}

Because of increasing concern and attention to health, functional foods and dietary supplements have been gaining popularity and prominence for their role in disease risk reduction and benefit to health in the recent past. This development has become a hot research area in academia and the industry. As in the biotechnological and pharmaceutical industries, research and development of health food products are often risky and require enormous resources.

Herbal therapies, just like all other products or medicines, also can be included from copying or being stolen through getting diverse forms of rights from the authorities. In view that the different rights are granted by way of the national government for an asset that has been invented for the betterment of human lifestyles from the use of thoughts or intellect, these are known as intellectual assets rights.

Four unique kinds of highbrow belongings rights (IPRs) are possible, namely patents, emblems, designs, and copyrights:

Different aspects of the license

Copyrights for herbals related matter

Trade marking for herbal products

Design registrations Infringement

As per Alice Yuen-Ting Wong et al. [1], FDA's regulation is essential for safety and labeling of functional foods and dietary supplements. Health claims and misleading labeling are significant issues. Natural matters are not patent-eligible in the U.S. Only useful, novel, non-obvious, fully described and enabled inventions are patentable.

Ari Feinstein et al. stated that globally [2], the nutraceutical industry is worth more than $\$ 200$ billion. It is a dynamic industry with a growing rate of large-scale mergers and acquisitions. For example, in August 2017, the private equity firm HGGC acquired dietary supplements manufacturer Nutraceutical International Corporation in a transaction valued at approximately $\$ 446$ million. A few months later, Innophos Holdings purchased ingredient supplier Nutra Genesis for \$28 million.

Intellectual property rights are an essential consideration in the nutraceutical industry. Investment in intellectual property rights, such as patents, trademarks, and trade secrets, both protects

\section{Journal of \\ Clinical Trials \& Patenting}

\author{
Raúl H. Morales-Borges* \\ ${ }^{\prime}$ Integrative Optimal Health of Puerto Rico, San Juan, Puerto Rico
}

*Address for Correspondence:

Raúl H. Morales-Borges, Integrative Optimal Health of Puerto Rico, San Juan, Puerto Rico, Tel: (787) 722-0412; Fax: (787) 723-0554; E-mail: raul.morales.borges@gmail.com

Submission: 03 July, 2019

Accepted: 10 July, 2019

Published: 12 July, 2019

Copyright: @ 2019 Raúl H, et al. This is an open access article distributed under the Creative Commons Attribution License, which permits unrestricted use, distribution, and reproduction in any medium, provided the original work is properly cited.

nutraceutical innovators from competitors and makes companies more valuable and attractive to investors.

Apart from protecting their intellectual property, nutraceutical companies also should be aware of the risk of having the intellectual property rights of others asserted against them. In 2013 alone, ThermoLife International filed 117 patent infringement suits. Similarly, the Tawnsaura Group brought nearly 100 patent infringement suits over 13 months. Thus, before launching a new product, a nutraceutical company should consider: 1) the types of intellectual property protection that may be available-namely, patents, trademarks, and trade secrets, and 2) whether there are any freedom-to-operate issues [2].

There are many different ways to cover a soon-to-be-launched nutraceutical product with patent protection. Patents may be obtained on a new chemical compound or further use of a known compound or a unique combination of known compounds. Processing or manufacturing techniques may also be patented. Patents for new and non-obvious compositions, formulations, methods of use, or manufacturing techniques are referred to as "utility patents." A "design patent" may also be obtained to cover the ornamental features of a new and non-obvious design-for example, for bottles or another packaging.

Before sharing information with anyone outside the company (who has not signed a non-disclosure agreement), the company should consider filing a "provisional" patent application. Provisional applications are not required but may provide potential benefits to innovators. Provisional applications allow a company to hold its place in line for up to 12 months while determining whether there is sufficient market demand for the innovation through public disclosures that could impact its ability to obtain patent rights. This 12-month period also provides time for additional research and development that may be needed. Within 12 months of filing, a provisional application must be converted to a regular "nonprovisional" patent application. Filing a provisional application can also be less expensive than a formal non-provisional patent application, which must meet specific requirements. In contrast to a non-provisional form, a provisional application could consist solely 
of a research proposal or a presentation for potential investors.

Once a non-provisional patent application is filed, the U.S. Patent \& Trademark Office's ("PTO") inquiry into whether the invention is patentable will begin. Although this process may be accelerated with the payment of specific fees, typically it will take several years before the negotiation between the PTO and an applicant is complete, ideally resulting in an issued U.S. patent.

Importantly, not all inventions can be patented. Abstract ideas, natural phenomena (including physical products), and laws of nature cannot be patented. However, it is possible to obtain patents on subject matter that relates to a natural phenomenon, but that also, for instance, transform the natural event by adding some "inventive concept." In a recent case, a U.S. federal district court determined that a patent claim reciting a dosage range of beta-alanine was invalid because beta-alanine is a natural phenomenon and ingesting it in a supplement form is not "inventive." Alternatively, a transformative inventive concept related to beta-alanine could include, for example, use of beta-alanine to treat a particular condition that was not known or expected to be treatable by beta-alanine, a composition of betaalanine that provides superior properties (for example, increased absorption), or a structure of beta-alanine with another ingredient that provides a synergistic effect (either for the beta-alanine or for the other active ingredient). As another example, the hydrolysis of a protein in acid is not, by itself, patentable. However, a method of increasing the rate of protein hydrolysis in water with a catalyst (a new and non-obvious way) may be patentable.

Nassia Kioukia-Fougiaa et al. [3]. Performed an excellent review of publications about nutritional supplements and patents for prevention, therapy, protection of the immune system, diabetes, oxidative stress, cancer, chronic inflammations, and other health conditions. Cases of making impure or unintentional contamination of commercial products with abusing substances (doping substances, narcotics, etc.) or toxic compounds (heavy metals, plant toxins) have shed light to the problem of causing recalls of some products by the FDA. So, they concluded that from the safety/quality point of view, natural supplements lack harmonization and leadinglaws/institutional controls on the market and their broad commercialization may lead to risks to public health.

Interestingly, P. Daliu et al. stated that the industry of nutritional supplements represents a provocation for the future of pharmacological treatments $[4,5]$, and, at the same time, are a powerful instrument for the chronic disease prevention. They are not proposed as an alternative to drugs, but instead, can be helpful to adjunct a drug therapy and prevent the onset of chronic diseases in subjects who do not qualify for conventional pharmacological treatment.

So, this hot topic is crucial, and issues should be revisited. Many patients are seeking complementary and alternative medicine, including herbal therapies, nutritional supplements, and special diets within others; considerable benefits are seen in our clinical practices.

\section{References}

1. Yuen-Ting WA, Chu Lai JM, Wai-Kit CA (2015) Regulations and protection for functional food products in the United States. J Funct Foods 17: 540-551.

2. Feinstein A, Jardine J, Caleb Bates of Knobbe Marten (2018) Intellectual property in nutraceuticals: Patents, trademarks, and trade secrets. Trends \& Business (/trends-business), Regulatory (/regulatory) 21: 1-3.

3. Kioukia-Fougia N, Georgiadis N, Tsarouhas K, Vasilaki F, Fragiadaki P, et al. (2017) Synthetic and Natural Nutritional Supplements: Health "Allies" or Risks to Public Health? Recent Pat Inflamm Allergy Drug Discov 10: 72-85.

4. Daliu P, Santini A, Novellino E (2018) A decade of nutraceutical patents: where are we now in 2018? Expert Opin Ther Pat 28: 875-882.

5. Daliu P, Santini A, Novellino E (2019) From pharmaceuticals to nutraceuticals: bridging disease prevention and management. Expert Rev Clin Pharmacol 12: 1-7. 